1 Breakthrough dynamics of s-metolachlor metabolites in drinking water wells:

2 transport pathways and time to trend reversal.

3 J.Farlin, T. Gallé, M. Bayerle, D. Pittois, S. Köppchen, M. Krause, D. Hofmann

\title{
4 Abstract
}

5 We present the results of a two years study on the contamination of the Luxembourg Sandstone aquifer by metolachlor-ESA and metolachlor-OXA, two major transformation products of s-metolachlor. The aim of the study was twofold: (i) assess whether elevated concentrations of both transformation products (up to 1000 ng/l) were due to fast flow breakthough events of short duration or the signs of a contamination of the entire aquifer and (ii) estimate the time to trend reversal once the parent compound was withdrawn from the market. These two questions were addressed by a combined use of groundwater monitoring, laboratory experiments and numerical simulations of the fate of the degradation products in the subsurface. Twelve springs were sampled weekly over an eighteen month period, and the 
water limit of $100 \mathrm{ng} / \mathrm{l}$ however is expected to last up to twelve years. The calculated contribution to total water discharge of the fast-flow component from cropland and short-circuiting the aquifer was small in most springs (median of $1.2 \%$ ), but sufficient to cause additional peaks of concentration of several hundred nanograms per litre in spring water. These peaks are superimposed on the more steady contamination sustained by the baseflow, and should cease immediately once application of the parent compound stops.

\section{Introduction}

The contamination of groundwater by pesticide transformation products (TPS) has recently emerged as an area of concern after these compounds were found to be ubiquitous in many aquifers (Hladik et al., 2008; Loos et al., 2010; Reemtsma et al., 2013). TPs often reach higher concentrations than their parent compound because they are in many instances more mobile (Boxall et al., 2004; Hanke et al., 2007; Kolpin et al., 1997; Kolpin et al., 2004) and less susceptible to degradation both in the unsaturated and saturated zone (Postigo and Barceló, 2015). This higher mobility and the potential for an additional production of TPs in the subsurface through microbial degradation of the parent compound (Farlin et al., 2017) may pose a serious threat to groundwater resources, and calls (i) for a comprehensive assessment of the transformation pathways and the fate of transformation products in the subsurface and (ii) for their inclusion in groundwater quality monitoring programs. Even in the case of "non-relevant metabolites" as defined by the European Union (1998), it may be important for authorities and water suppliers to "be aware of organic contaminants in the raw waters used for drinking water production" (Reemtsma et al., 2013). 
The widespread contamination of s-metolachlor's transformation products in groundwater has first been reported about two decade ago in the United states of America (Kalkhoff et al., 1998) where the parent compound had been used for longer than it has in Europe (Baran and Gourcy, 2013). The positive detections of these initial surveys prompted further studies on the environmental fate of s-metalochor and other chloroacetamides. S-metolachlor is classified as moderately mobile with low persistence (Lewis et al., 2016) but its sulfonic metabolite metolachlor-ESA (MESA) and to a minor degree its oxanilic metabolite metolachlor-OXA (MOXA) are much more mobile and persistent, at least in unsaturated media (Baran and Gourcy, 2013; Sidoli et al., 2016). This difference in mobility was clearly illustrated in a study in Lake Greifensee in Switzerland where s-metolachlor was clearly allocated to event-driven surface runoff while MESA was discharged via groundwater and at much higher concentrations (Huntscha et al., 2008). The degradation rates of s-metolachlor and the formation fractions of the TPs (i.e. the percentage of degraded parent compound transformed into a given TP) have been measured in several studies under aerobic and anaerobic conditions providing a range of parameter values (Aga and Thurman, 2001; Dinelli et al., 2000; Graham et al., 1999; Krutz et al., 2006). Modelling studies of pesticide fate in different agricultural settings could predict the shallow groundwater occurrence of MESA with reasonable success (Bayless et al., 2008). In order to explore the spatial variability of MESA leaching, simulations were performed for aquifers displaying different unsaturated zone thicknesses, physical properties and pesticide applications (Hancock et al., 2008; Webb et al., 2008). Testing these simulations with positive detections of the investigated compounds in groundwater is however impeded by the nonsteady application of the pesticides (Kraft et al., 2008). Hence, although a certain body of evidence exists concerning the widespread 
occurrence of MESA in groundwaters and first successful simulations on its behavior in regional settings were achieved, the need for more in depth studies for specific aquifers remains. This is not only due to hydrogeological specificities but also to the variability of degradation half-lives of parent compounds and transformation products as well as sorption properties which are major sources of uncertainty for modelling (Dubus et al., 2003).

In Luxembourg, MESA and MOXA contamination of drinking water springs began to be reported seven years after a country wide ban of the herbicide atrazine caused an increased use of alternative herbicides in corn cultures, including s-metolachlor, and lead the water administrations to consider a ban of the compound in groundwater protection zones. The aim of the study presented here was to determine whether the occurrence of MESA and MOXA in spring water was due to breakthrough events of short-duration caused by fast-flow surges, or if base flow was a major transport pathway, indicating that the entire aquifer was under threat from a long-term contamination. In the latter case, estimates of the time to trend reversal and the waiting time until water quality standards were restored in the contaminated springs was essential to the water providers and the water administration.

\section{Case study}

The fractured-rock aquifer known locally as the Luxembourg Sandstone provides about half of the drinking water requirements of the country of Luxembourg. The sandstone formation, up to 80 meters thick and underlain by a marly aquiclude, forms a series of cuestas. Numerous contact springs emerge where the sandstone basis intersects the land surface. Most springs are tapped and used as raw water supply. Large fractures visible in outcrops lead earlier researchers to suppose fast conduitlike flow and a double porous system consisting of a porous sandstone matrix and a 
hydraulically active fracture network, but recent evidence rather points to a hydraulic behaviour closer to an equivalent porous medium at the scale of each groundwatershed, at least for the baseflow component which seems to sustain discharge nearly completely (Farlin et al., 2017; Farlin et al., 2013a; Farlin et al., 2013b). Fast flow breakthrough estimated using stable isotopes in a series of springs sampled weekly between 2008 and 2010 were rare and never exceeded 15\% of total discharge (Farlin et al., 2013b). Mean transit times calculated with lumped-parameter models calibrated using tritium measurements (Maloszewski and Zuber, 1982) ranged from 9 to 17 years in a series of springs studied by Farlin et al. (2017).

MESA and MOXA concentrations in springs draining the Luxembourg Sandstone exceeding the legal drinking water limit of $100 \mathrm{ng} / \mathrm{l}$, sometimes by a factor 15 , had begun to be reported prior to the study in 2011 and 2012. The parent compound smetolachlor is a pre-emergence herbicide used in corn crops, whose use has probably increased significantly after atrazine, which for decades had been the main herbicide for corn cultures, was banned from use in 2005. Corn is a major crop in many water protection zones, occupying on average $25 \%$ of their surface areas, all crop rotation frequencies together. Both atrazine and one of its TP, desethylatrazine (DEA), were found in many springs draining the aquifer in the first countrywide sampling campaign in 2007 , for the latter at concentrations sometimes exceeding the legal limits. Following the atrazine ban, atrazine and DEA concentrations have steadily decreased, although concentrations above the quantification limit of $5 \mathrm{ng} / \mathrm{l}$ were still common in 2014, especially for DEA. In response to the increasing evidence of a potential major contamination of the aquifer by MESA, s-metolachlor was withdrawn from the market countrywide in 2015. 
123 Land use in the recharge area of the Luxembourg Sandstone is essentially rural, with an average of $60 \%$ of the total surface area occupied by woodland and $30 \%$ by cropland and pastures. Soils are highly permeable sands grading to sandy loams in some areas. Surface runoff is negligible on such permeable soils and herbicide sorption to soil organic matter limited, given the low organic matter content in those soils. Soil organic carbon content measured on one of the cuestas ranged from 0.5 to $2.3 \%$ with a mean value of $1 \%$ (Farlin et al., 2013c). This mean value is similar to the soil organic carbon content given for these soil types by the general soil map of the Luxembourgish agricultural services (ASTA, 2015), so the measured range should be representative of the entire recharge area of the Luxembourg Sandstone.

Twelve springs draining the Luxembourg Sandstone were selected for the study on the following criteria

1. Known elevated MESA concentrations weekly from May 2013 to July 2014. Temperature, electric conductivity and discharge 
and water stable isotopes measurements (oxygen 18 and deuterium) using one litre glass bottles. Weekly stable isotope concentration in rainwater was also sampled using a Hellmann rain gauge set up close to spring 10. Additional data on MESA, in July 2017. Spring numbering as it appears on the map of Figure 1 will be used throughout the text.
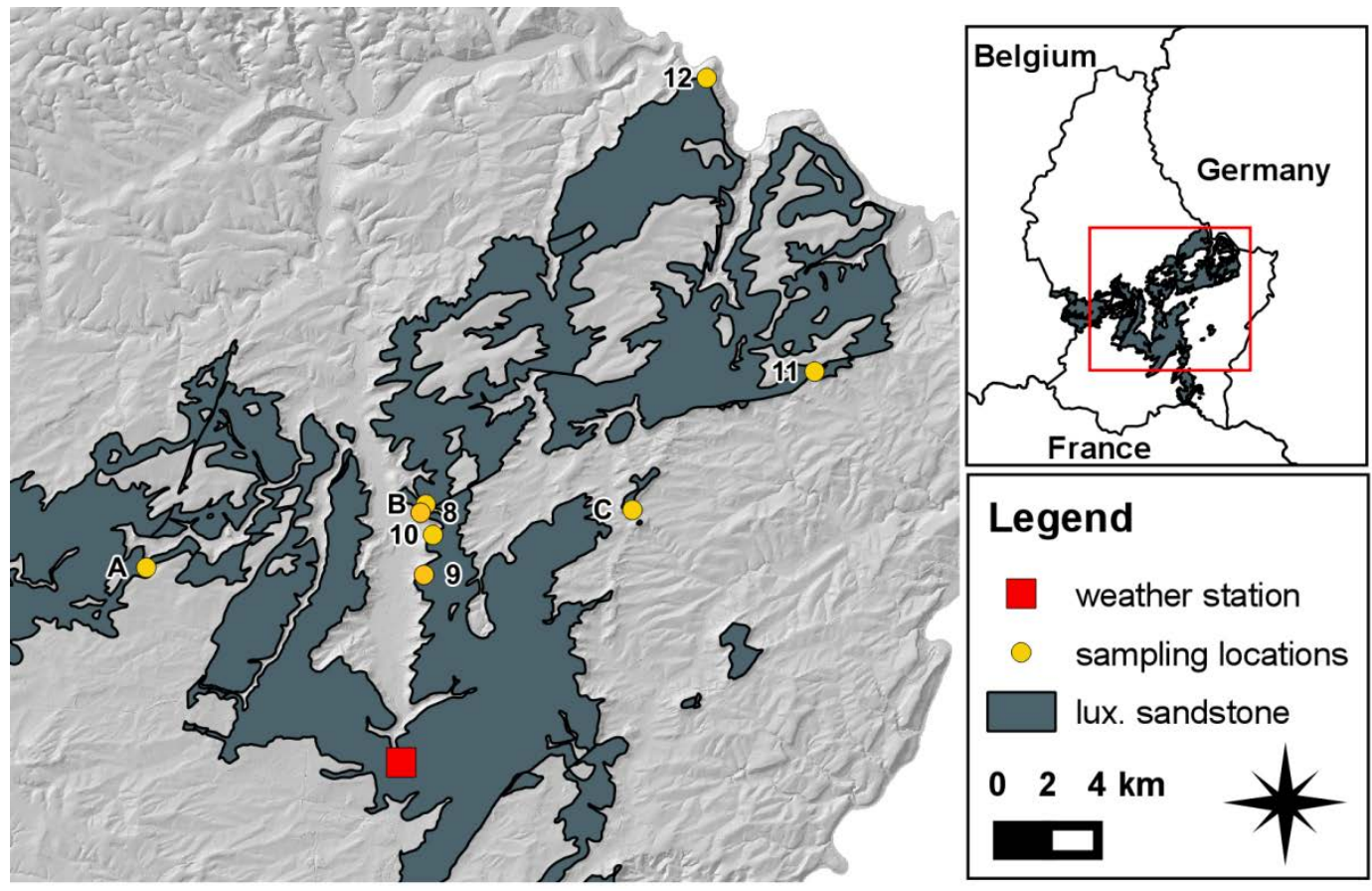

Figure 1. Overview of the sampling sites. The extent of the unconfined part of the

Luxembourg Sandstone is shown in grey.

\section{Method}

\subsection{Overall methodology}

160 The method adopted makes a combined use of the data collected during the weekly sampling of the springs and the laboratory degradation experiments and numerical simulations and is structured as follows:

1. The degradation experiments yield an estimate of the field half-life of smetolachlor, MESA and MOXA (section 3.4). 
2. Pesticide fate in soil is simulated with the numerical code PEARL using the laboratory field half-life values, and yields prediction of the leachate concentration and leachate dynamics for MESA and MOXA (section 3.5).

3. The time series of MESA and MOXA in spring water is finally separated into its base flow and fast flow components using the predicted soil leachate concentration and dynamics and a lumped parameter model approach to simulate the aquifer's reaction to repeated leaching over several years (section 3.6 and 3.7).

The methods adopted for each step will be presented in a dedicated section below.

\subsection{Conceptual model of the aquifer}

In this study, we assume that total springs discharge is sustained at any moment by two distinct reservoirs. The first reservoir corresponds to the aquifer itself, and its contribution is further referred to as "base flow". The second reservoir, characterised by a smaller volume and consequently a quicker response to rainfall, comprises all potential flow paths at the exclusion of the permanently saturated zone, including the soil bedrock interface, superficial fracture networks only activated by infiltration excess mechanisms or transient perched water tables forming where marly lenses are present in the subsurface. Since the precise mechanism (or mechanisms) controlling the observed fast flow breakthroughs cannot be determined in the experimental setup, we will in this article refrain from interpreting "fast flow" mechanistically other than in terms of a contribution to spring discharge that cannot be explained by a single slow flow component.

At any given moment, total spring discharge is sustained by the sum of the base flow and fast flow contributions. These contributions can vary over time, and so can the MESA and MOXA concentrations of each reservoir. Conceptually, this last point sets 
the approach apart from a classic end-member analysis where each reservoir (the end-members) are characterised by solute concentrations that are different, but constant over time (Christophersen et al., 1990). In practice however, we will see that the time variable concentrations of the end-members are difficult to parameterize.

\subsection{Pesticide quantification in water samples}

Pesticide concentrations of the spring water samples have been determined using a LC-ESI-MS/MS system Finnigan TSQ Quantum Discovery MAX. Using an onlineconcentration method, the analysis could be carried out directly from the filtered water sample. Therefore, an extraction or trapping column (Hypersil Gold, 20 x 2,1 $\mathrm{mm}$, particle size $12 \mu \mathrm{m}$ from Thermo Scientific, Bonn, Germany) has been interconnected between the autosampler injection valve and the chromatography column. Per measurement cycle, $1 \mathrm{ml}$ are injected and extracted with the trapping column. Afterwards, the target compounds are separated in the chromatography column and analyzed with the above-mentioned triple quad mass spectrometer. The separation of the target compounds was carried out with a column Hypersil Gold aQ, $100 \times 2.1 \mathrm{~mm}$ with $3 \mu \mathrm{m}$ particle size (Thermo Scientific, Bonn, Germany). Elution was started with 70/30 ultrapure water (18 M $)$ ) / Methanol (acidified with $0.1 \%$ formic acid) with a flow rate of $0.2 \mathrm{ml}$ per minute. During the acquisition, Methanol was increased to $100 \%$. A seven-point calibration ranging from $5 \mathrm{ng} / \mathrm{L}$ to $400 \mathrm{ng} / \mathrm{L}$ has been prepared in pure water and measured at the beginning of each sequence. After ten samples a quality control sample (QC) and a blank has been injected to control for the stability of the system. Limits of quantification (LOQ) were $5 \mathrm{ng} / \mathrm{L}$ for DEA and $25 \mathrm{ng} / \mathrm{L}$ for MESA and MOXA.

\subsection{Degradation experiments}




\section{Table 1. Texture of the soil used for the degradation experiments}

\begin{tabular}{lc}
\multicolumn{1}{c}{ Fraction size } & percentage \\
\hline clay $(<2 \mu \mathrm{m})$ & $8 \%$ \\
fine silt $(0.002-0.006 \mathrm{~mm})$ & $6 \%$ \\
medium silt $(0.006-0.02 \mathrm{~mm})$ & $12.50 \%$ \\
coarse silt $(0.02-0.063 \mathrm{~mm})$ & $16.70 \%$ \\
sand $(0.063-2 \mathrm{~mm})$ & $56.80 \%$ \\
\hline
\end{tabular}

Soil water content was kept constant at $15 \%$ of field capacity in each flask which 
at regular intervals, and pesticides extracted using a 0.1 molar calcium chloride

233 solution for the mobile fraction and by accelerated solvent extraction (ASE, ThermoFisher Scientific, formerly Dionex) for total extraction. ASE was performed at a temperature of $80^{\circ} \mathrm{C}$ in one cycle with a pure acetonitrile solution. ASE recovery determined on spiked soil samples was $60 \%, 80 \%$ and $40 \%$ respectively for smetolachlor, MESA and MOXA.

The radioactivity of the three compounds was determined by radio-HPLC. In order to improve the sensitivity of the TPs after ASE, the extracts were pre-concentrated by a factor 5 before measurement using a rotary evaporator.

The HPLC analysis of metolachlor and his metabolites was performed using a binary pump system (Gynkotek), equipped with autosampler, column oven $\left(25^{\circ} \mathrm{C}\right)$ and radiodetection (LB 509, Berthold with integrated YG-150 U4 solid scintillator measuring cell). Analyses were run using a reversed-phase Zorbax Eclipse Plus C18 column $(150 \mathrm{~mm} \times 4.6 \mathrm{~mm} \times 5 \mu \mathrm{m}$, Agilent). Solvent A was Millipore water (Millipore $\mathrm{GmbH}$, Schwalbach, Germany), buffered with $0.1 \%$ phosphoric acid, as solvent B acetonitril (Merck Lichrosolv, $\geq 99.9 \%$ purity) was used. The separation was performed with following gradient program: 0 to 2 min: $10 \%$ solvent B, from 2 to 25 min linear from 10 to $100 \%$ solvent B, 25 to 28 min hold $100 \%$ solvent B, from 28 to 32 min switch back to starting conditions. The flow rate was $1 \mathrm{ml} \mathrm{min}^{-1}$, injection volume $250 \mu \mathrm{L}$. Limit of quantification (LOQ) was 50 Bq per peak. Retention times were $11 \mathrm{~min}$ (MESA), $14.8 \mathrm{~min}$ (MOXA) and $20.2 \mathrm{~min}$ (metolachlor), respectively.

The transformation rates and formation fractions were finally estimated assuming first order kinetics by least square fitting using the following system of equations

(1) $\quad A_{P C}=A_{P C}^{0} \cdot r_{P C} \cdot e^{-\lambda_{P C} t}$ 
(2) $\quad A_{T P}=\frac{f_{T P} \lambda_{P C}}{\lambda_{T P}-f_{T P} \lambda_{P C}} A_{P C}^{0} \cdot r_{T P} \cdot\left(e^{-\frac{\lambda_{T P}}{f_{T P}}}-e^{-\lambda_{P C} t}\right)$

257 where $A$ is activity $[\mathrm{Bq} / \mathrm{g}], r$ is the ASE recovery ranging between 0 and $1[-], \lambda$ the 258 reaction rate $[1 / d]$ and $f$ the fraction of parent compound transformed into a given metabolite. The subscripts PC and TP stand respectively for parent compound and transformation product.

The half-life, which is the waiting time until half of the compound mass has been

262 degraded is

263

(3) $\quad D T 50=\frac{\ln (2)}{\lambda}$

3.5 Modelling MESA and MOXA soil dynamics and leaching

The leaching of s-metolachlor and its two transformation products as well as DEA leaching was calculated using the code PEARL, which simulates chromatographic, variably saturated flow and solute transport in a one-dimensional soil column at daily time steps (Leistra et al., 2001). Sorption is simulated with a Freundlich isotherm, degradation follows a first-order kinetic law. The fate of one parent compound and up to two transformation products can be simulated simultaneously. PEARL comprises a

271 crop growth module and integrates a library where the most common European crops are fully parameterized, including corn. Table 2 summarises the soil parameterisation used for modelling and the calculated water balance.

Table 2. Summary of the parameterisation and water balance of PEARL

Hydraulic parameters

Meteorological data
HYPRES coarse soil

station Findel, Luxembourg City (2001- 
Average annual precipitation [mm] 830

Average annual recharge $[\mathrm{mm}] \quad 310$

Organic carbon content [\%] $\quad 1(0-30 \mathrm{~cm}) 0.5(30-60 \mathrm{~cm}) 0.1(60-100 \mathrm{~cm})$

Weighting of the DT50 with depth $\quad 1(0-30 \mathrm{~cm}) 0.5(30-60 \mathrm{~cm}) 0.3(60-100 \mathrm{~cm})$

Average actual evapotranspiration

$[\mathrm{mm}] \quad 520$

Simulated application frequencies annual-triennial

3.6 Modelling pesticide concentrations in the base flow

Due to the different length of the flow lines connecting each agricultural plot to the springs, a pesticide pulse reaching the water table at approximately the same time following a rainfall event (i.e. for negligible or nearly equal transit times through the unsaturated zone) will arrive at the outlet of the groundwatershed spread out in time. The transformation of the input signal into an output signal due to the transit time distribution of the flow paths is simulated using a convolution integral (Maloszewski and Zuber, 1982). This transit time distribution or weighting function must be chosen from available models to represent as best as possible the local hydrogeological situation. Following Farlin et al. (2017), the exponential piston-flow model (EPM) was used as weighting function. The convolution integral giving the relationship between the TP input concentration $C_{\text {in }}$ (soil leaching calculated with PEARL) and the TP output concentration Cout is

$$
C_{\text {out }}(t)=\int_{-\infty}^{t} C_{\text {in }}(\tau) g(t-\tau) d \tau
$$

Where $g$ is the transit time distribution, in that case the EPM, which is defined as follows (Maloszewski and Zuber, 1982) 


$$
g(\tau)=0 \quad \text { for } 0<\tau<\frac{\eta-1}{\eta} T_{e p m}
$$

293 with $\eta=\frac{T_{e m}+T_{p f}}{T_{e m}}, \tau=$ time [y] $T_{p f}=$ mean transit time in the unsaturated zone [y], $T_{e m}$ $294=$ mean transit time in the saturated zone $[\mathrm{y}]$ and $T_{e p m}=$ total mean transit time $\left(T_{e m}+T_{p f}\right.$ $295 \quad$ ).

296 Because the pesticide or TP concentrations in recharge water depends on the treatment frequencies, contaminant concentration in the outlet is the sum of the contribution from the different contributing surfaces divided by application frequency

$$
C_{\text {out }, \text { pest }}(t)=\frac{b}{R} \sum_{i=1}^{n} a_{i} \int_{-\infty}^{\mathrm{t}} \mathrm{M}_{\mathrm{in,} \mathrm{pest}}^{i}(\tau) \mathrm{g}(\mathrm{t}-\tau) \mathrm{d} \tau
$$

Where i=application frequency (1=every year, $2=$ once every two years, etc) [1/y], $a_{i}=$ fraction of the total surface area of the groundwatershed treated at the corresponding application frequency $[-], b=$ factor simulating the additional formation of TPs in the subsurface by degradation of the parent compound (Farlin et al., 2013b), M=leached mass by unit surface $\left[\mathrm{kg} \cdot \mathrm{d}^{-1} \cdot \mathrm{m}^{-2}\right], R=$ recharge over the entire simulation period $\left[1 \cdot \mathrm{d}^{-1} \cdot \mathrm{m}^{-2}\right]$. Calculations are performed at a daily time step. In order to reduce the number of fitting parameters, the function $\mathrm{g}$ is assumed to be the same for all application frequencies. The method also assumes that the agricultural surfaces are contiguous and separated from the outlet of the groundwatershed by "pesticide free" areas (untreated crop land or woodland). Two different waiting times are of interest in the case of aquifer contamination: 
- The waiting time $T_{2}$ until contaminant concentrations have reached a target level, which can be the limit of detection, a drinking water standard, or a concentration low enough to allow mixing with a less contaminated water supply

$\mathrm{T}_{1}$ is simply the mean transit time of the piston flow component $T_{p f}$ (i.e. the time shift between a change in the input and the output response). $T_{2}$ depends on $T_{p f}, T_{e m}$ and on the initial and final contaminant concentrations $\mathrm{c}_{\mathrm{t}_{0}}$ and $\mathrm{c}_{\text {target }}$ as follows

(7) $\mathrm{T}_{2}=-\mathrm{T}_{\mathrm{em}} \cdot\left[\ln \left(\mathrm{c}_{\text {target }}\right)-\ln \left(\mathrm{c}_{\mathrm{t}_{0}}\right)\right]+\mathrm{T}_{\mathrm{pf}}$ where $c_{\text {target }}$ =target concentration $\left[\mathrm{M} / \mathrm{L}^{3}\right]$.

\subsection{Estimation of the fast flow contribution}

The contribution of reservoirs with different tracer concentrations to total discharge can be estimated using the following equation (Maloszewski et al., 2002)

(8) $\quad Q_{\text {ff }}(t)=\frac{Q_{\text {total }}(t) C_{\text {total }}(t)-Q_{b f}(t) C_{b f}(t)}{C_{f f}(t)}$

Where $\mathrm{Q}$ is discharge $\left[\mathrm{L}^{3 / T}\right], \mathrm{C}$ is tracer concentration $\left[\mathrm{M} / \mathrm{L}^{3}\right]$, and the subscripts $\mathrm{ff}, \mathrm{bf}$ and total stand respectively for fast flow, base flow and total signal. If $\mathrm{Q}_{\mathrm{ft}}<<\mathrm{Qbf}$, we can set $\mathrm{Q}_{\text {total }} \approx \mathrm{Q}_{\mathrm{bf}}$ and thus equation (8) simplifies to

(9) $\frac{Q_{f f}(t)}{Q_{\text {total }}(t)}=\frac{C_{\text {total }}(t)-C_{b f}(t)}{C_{f f}(t)}=\frac{\Delta C(t)}{C_{f f}(t)}$

If the tracer used is a pesticide or a TP, $\mathrm{C}_{\mathrm{ff}}$ has to be weighted by the relative surface area of the groundwatershed where the compound originates, and equation (9) becomes

(10) $\frac{Q_{f f}(t)}{Q_{\text {total }}(t)}=\frac{C_{\text {total }}(t)-C_{b f}(t)}{C_{f f}(t)}=\frac{\Delta C(t)}{C_{f f}(t) \sum_{i=1}^{n} a_{i}}$ 
333 where $a_{i}=$ fraction of the total surface area of the groundwatershed treated at the corresponding application frequency [-] as in equation (6). Equation (10) also assumes that the leaching concentration is the same below all treated surfaces, regardless of the application frequency.

Conceptually, we suppose that the pesticide concentration in spring water is the sum of a slowly varying baseflow contribution and a highly variable and event driven fast flow contribution, the latter being responsible for pesticide breakthroughs in the months following crop treatment and superimposed upon the baseflow signal.

\subsection{Modelling strategy}

Modelling is performed in two stages. Firstly, the convolution model is fitted to the measured TP concentrations, yielding an estimate of the base flow contribution to the

344 total TP flux. Secondly, residuals computed from the difference between predicted base flow concentration and measured TP concentrations are attributed to the fast flow component and used to estimate the corresponding fraction of total water discharge (equation 10).

The convolution model calculating base flow concentration from the soil leaching time series has $n+3$ fitting parameters: $n$ fractions of the total surface area of the groundwatershed treated at different application frequencies (equation 6), the two parameters of the weighting function (equation 5) and the factor b simulating the addition of TPS below the topsoil by degradation of the parent compound in the unsaturated and saturated zones. The application frequency parameters are scaling 354 factors with which to adjust the predicted concentrations uniformly over the simulation 355 period, while the parameters of the weighting function control the rate and timing of change in TP concentration. 
357 Farlin et al. (2017) present a method with which to calibrate the transit time 358 distribution of pesticides using tritium and land use data. This approach however could not be adopted for the study presented here as only one tritium measurement was available for five of the sampled springs (at least two observations at an interval of a year are necessary to calibrate equation (4) using tritium data). Instead, the two free parameters of the transit time distribution function are estimated by directly fitting the time series of two TPS displaying a different evolution over time: MESA (increasing trend or no trend) and DEA (decreasing trend). The parameters of the transit time distribution were initially adjusted manually to match the decreasing DEA concentrations, and were then used to predict the MESA concentrations. Some additional adjustments were sometimes necessary to improve the MESA fit while retaining an acceptable DEA fit. If the DEA time series was too short or DEA below quantification limit, the weighting function was calibrated on the seasonal fluctuations of MESA by adjusting first $T_{e m}$ to the measured amplitude and then $T_{p f}$ to match the phase shift.

\section{Results}

\subsection{Degradation experiments}

The measured specific activities for all three measured compounds (s-metolachlor and its two TPs) over time are shown on Figure 2, together with the best fit curves. The activity of s-metolachlor is the total activity measured by ASE, whereas the measurements for the metabolites are from the calcium chloride extracts, as the ASE measurements were too noisy (but in the same range as the calcium chloride extracts), probably due to the pre-concentration step. This proved unproblematic in that particular case since the calcium chloride method is as efficient as the ASE extraction for mobile compounds (low Koc values) such as MESA and MOXA. This 
was verified by comparing ASE measurements and calcium chloride extracts measurements, which were in the same range (but much noisier for the ASE data). The estimated parameters are summarised in Table 1 together with the values taken from the PPDB database for comparison (PPDB, 2013). Estimated DT50 values are higher than typically reported for s-metolachlor, and shorter for the TPs, while the estimated formation fraction is half as high for MESA and 30\% higher for MOXA.

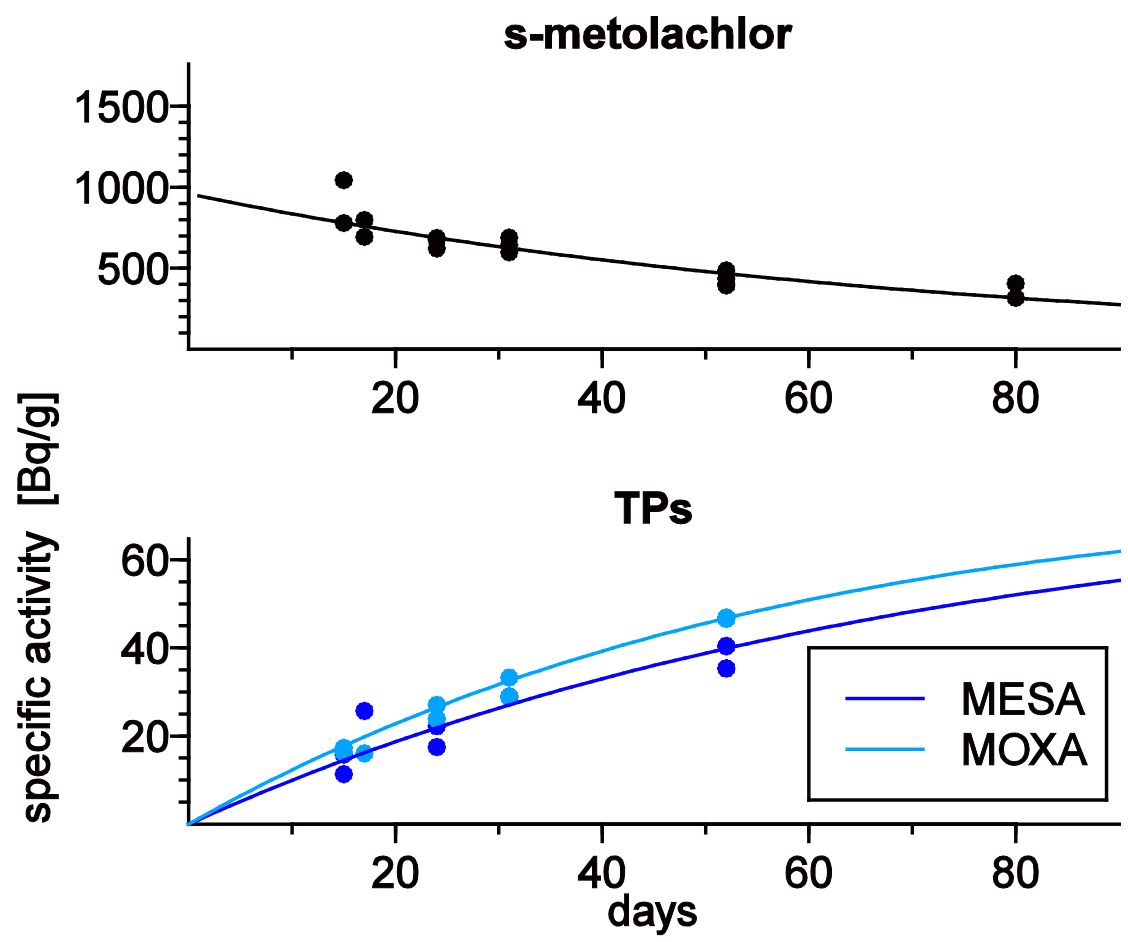

Figure 2. Observed degradation of s-metolachlor and formation of MESA and MOXA. Measurements were made in two replicates for each sampling date. Points: observations (two replicates for each date); lines: fitted model.

Table 3. Estimated degradation parameters. DT50 : degradation half-life,

$f=$ formation fraction. Minimum and maximum Koc values are given in brackets.

\begin{tabular}{c|c|c}
\hline DT50 [d] & Koc [L/kg] & $f[-]$ \\
s-metolachlor MESA MOXA & s-metolachlor MESA MOXA & MESA MOXA \\
\hline
\end{tabular}


project

The concentrations of MESA, MOXA and DEA in infiltration water were simulated with PEARL for three different application frequencies in corn (every year, every second year and once every three years). Treatment was assumed to take place on the $5^{\text {th }}$ of May at a dose of $1440 \mathrm{~g} / \mathrm{ha}(1000 \mathrm{~kg} / \mathrm{ha}$ for atrazine), which is the worst case corresponding to the maximum dosis recommended by the Luxembourgish

401

Chamber of Agriculture when s-metolachlor is applied as single formulation. The mean of applied s-metolachlor to corn calculated from state statistics was for 2012 stands at one tenth of this value with $150 \mathrm{~g} / \mathrm{ha}$ (SER, 2014). This difference can be explained by the use of other alternative herbicides on corn cultures, and indicates that on a countrywide average, about one tenth of corn surfaces were treated with smetolachlor.

The daily meteorological data covering the simulation period 2001-2014 were obtained from the national weather service for the weather station Findel (see Figure 1). All simulations were run from 2001 to 2020 by repeating the period 2001-2006 for the missing time span 2015-2020. S-metolachlor applications were assumed to have taken place between 2006 and 2014, i.e. from the ban of atrazine to the smetolachlor ban. In the absence of weather data before 2001, the same atmospheric forcing was used to calculate the leaching of DEA by shifting time backwards by 10 years (i.e. simulation from 1991 until 2010) with the last application taking place in 2005. In both cases, the first three years were used as warm up phase and discarded from analysis. 
417 The permeable soils overlying the aquifer were simulated by selecting the van

418 Genuchten parameters of a coarse soil taken from the HYPRES database (Wösten et

419 al., 1999). Leaching estimates are known to be particularly sensitive to DT50 and Koc

420 values (Boesten, 1991). In order to assess the effect of these parameters on the

421 predicted concentration, calculations were performed using DT50 and formation

422 fractions estimated both from the degradation study and the standard values from the

423 PPDB database. Similarly, minimum and maximum reported Koc values were also

424 used in the simulation to provide upper and lower bounds. The predicted MESA

425 concentration at a depth of one metre is shown exemplarily for an annual and

426 triennial application on Figure 3. Given its similar physico-chemical properties, the

427 predictions for MOXA are comparable and not shown here. According to simulations,

428 leaching from the soil takes place from November until March with a maximum in

429 December or January, depending on the prevailing meteorological conditions. The

430 time series for a triennial application shows that the longer soil half-life for s-

431 metolachlor estimated from the project's laboratory experiment lead to a second

432 leaching peak of MESA during the recharge period of the year following an

433 application (see Figure 3). MESA leaching in the third year after treatment is 434 negligible, thus a ban of the parent compound will lead to a rapid stop of MESA 435 release from the soil compartment. 


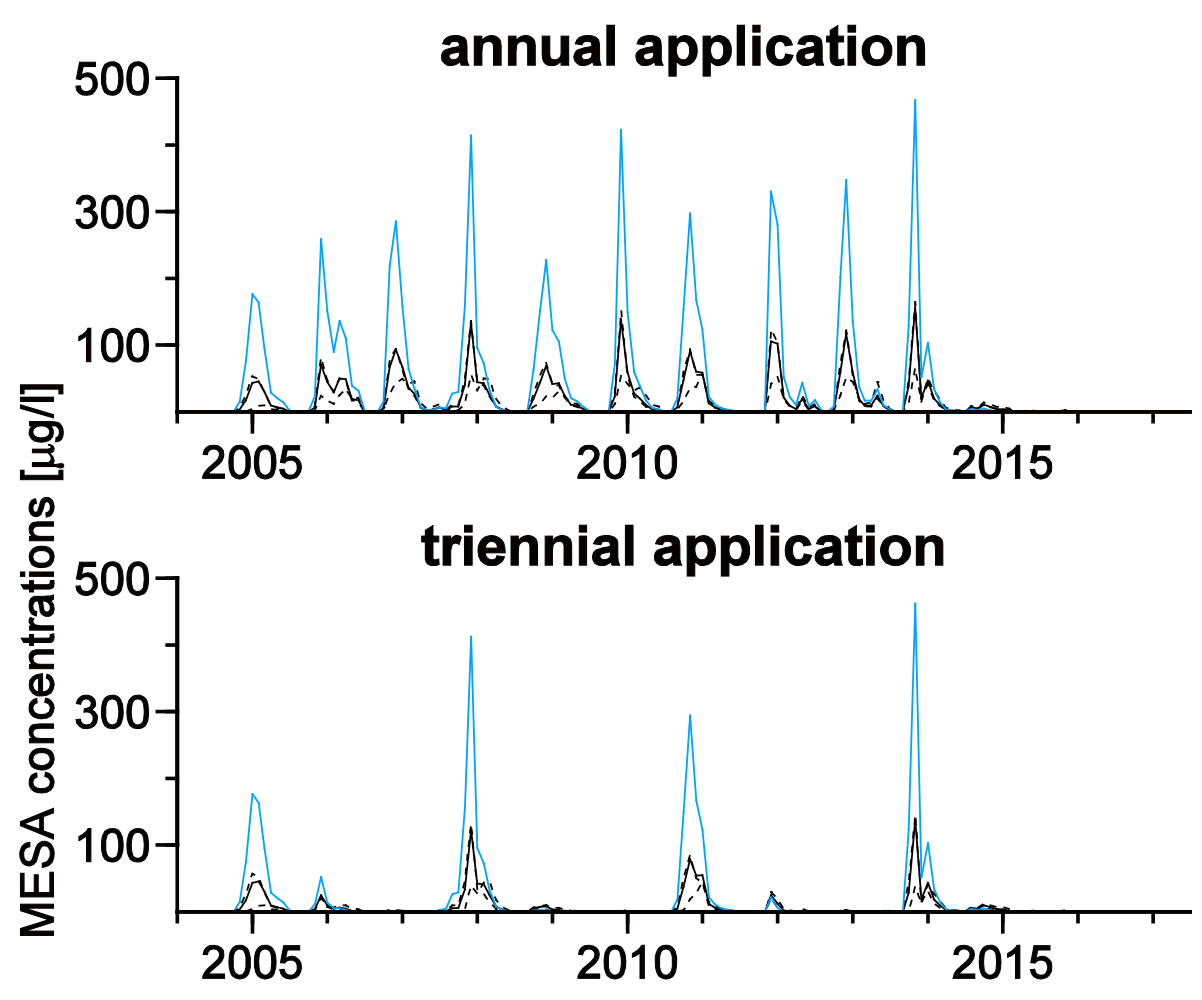

Figure 3. MESA concentration at a depth of 1 metre for an annual and triennial application. Black line: calculated concentrations using the DT50 values estimated from our degradation experiments. Blue line: DT50 values taken from the PPDB database. Dotted lines: maximum Koc values given in the PPDB database (used only for the DT50 estimated in the study). Leaching concentrations calculated using the minimum Koc values are nearly indistinguishable from the black line. Figure 4 and Figure 5 shows the evolution of MESA and MOXA concentrations over time. MOXA concentrations were below quantification or detection limits in seven of the sampled springs and lower than MESA concentrations by a factor 2 to 10 at the other sites. MOXA concentration was also increasing much faster than MESA concentration in spring 12. Absolute MESA concentrations as well as overall trends differ from spring to spring, going from a steady increase in spring 9 to a stable mean value in spring A2. In the case of both MESA and MOXA, seasonal trends appear 
451 clearly in some springs (A3, C1 and C2, 10 for MESA, all for MOXA except spring 12) overlain by additional shorter lived peaks for instance in spring 10 in March and April 2014 or in spring C2 in April of the same year (MESA). Relating these additional (paragraph 4.2) allows to estimate the transit time of the fast flow component to between two and five months.

A 1

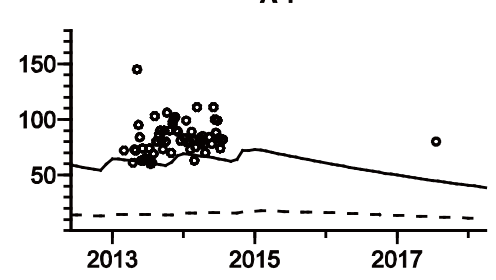

B 1

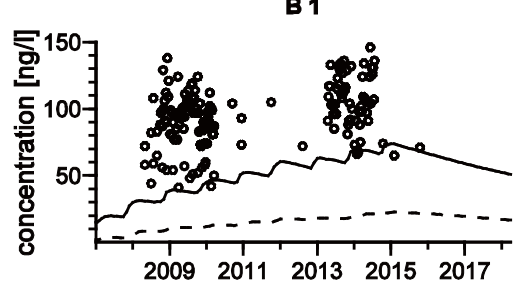

C 2

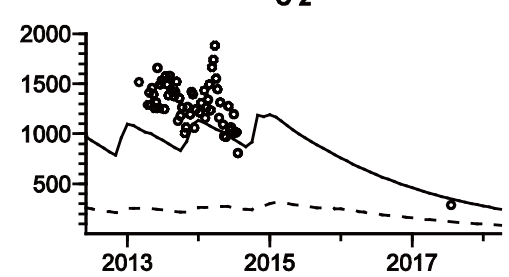

10

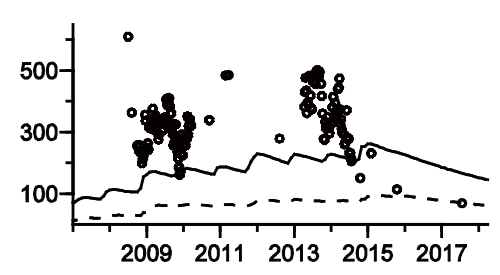

A 2

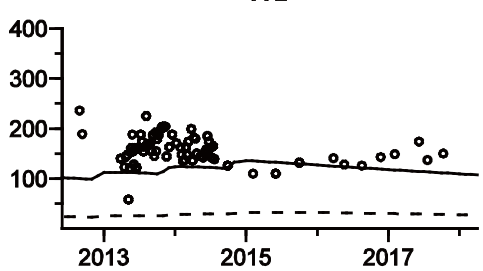

B 2

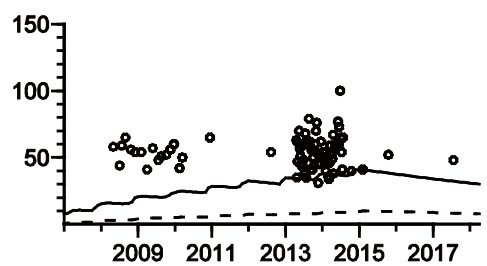

8

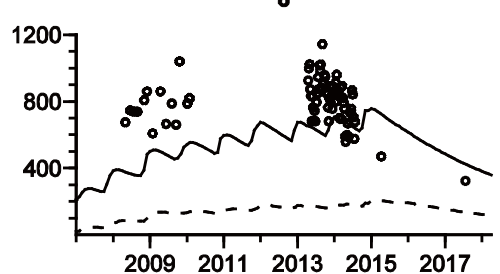

11

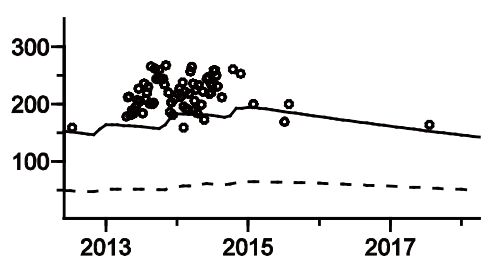

A 3

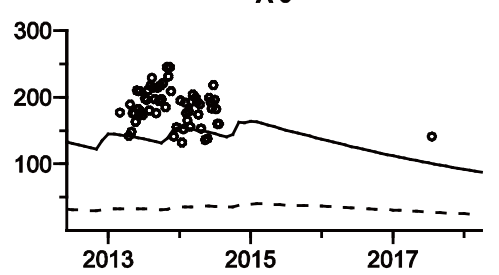

C 1

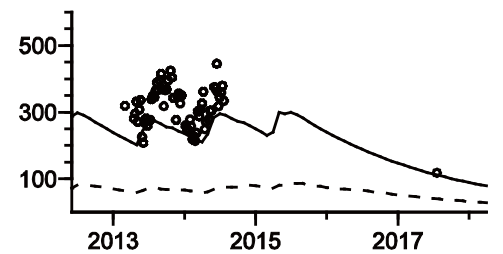

9

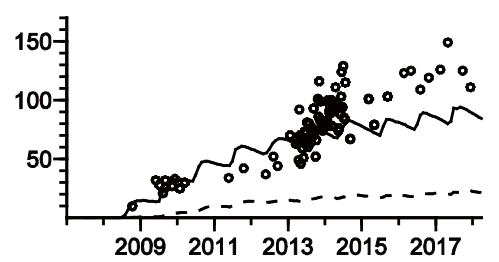

12

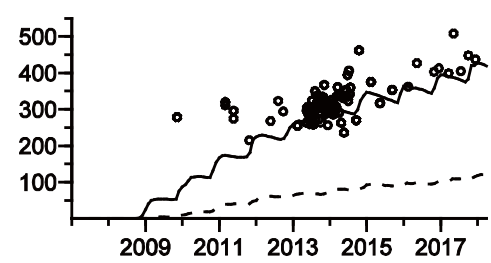

Figure 4. Observed MESA concentrations and fitted convolution model. Points : observations. Lines : calculated response of the aquifer using the convolution model. 
461 dotted lines: minimum/maximum Koc values. The aquifer response calculated using

462 the maximum Koc value is nearly indistinguishable from the black curve.
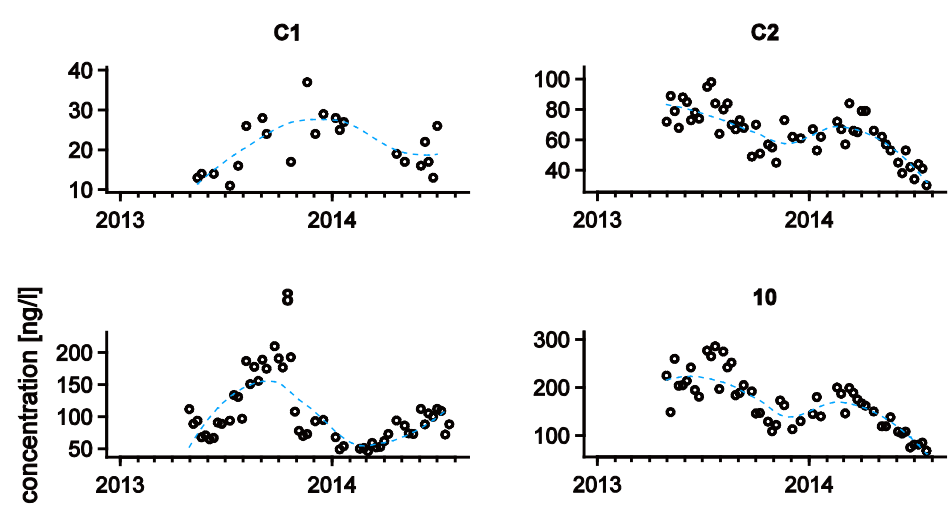

463

12

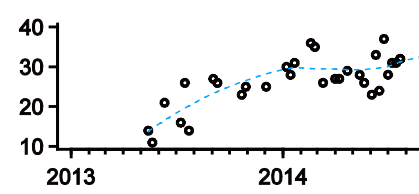

464 Figure 5. Observed MOXA concentrations over the sampling period. The dotted line 465 is a smooth designed to better show seasonal patterns. 
A 1

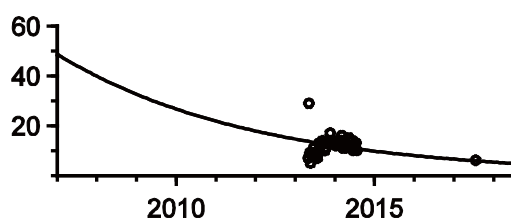

A 3

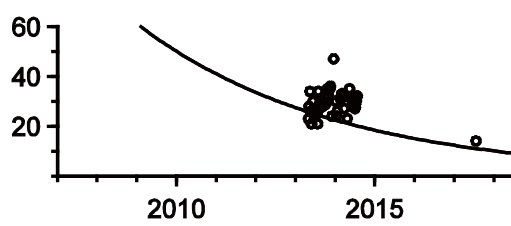

B 2

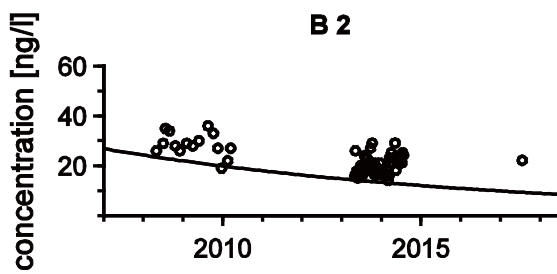

8

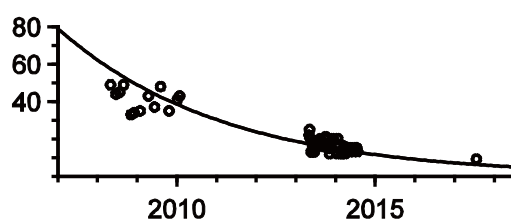

10

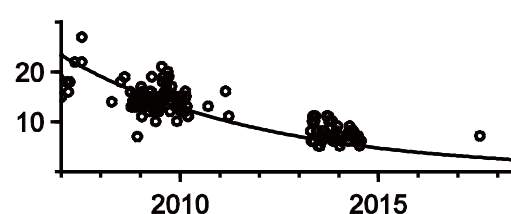

A 2

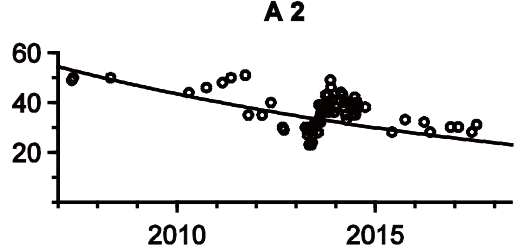

B 1

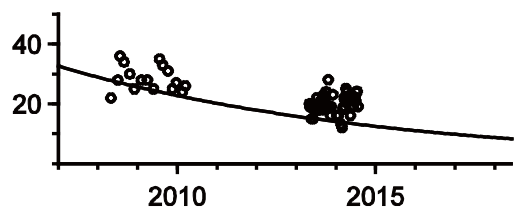

C 2

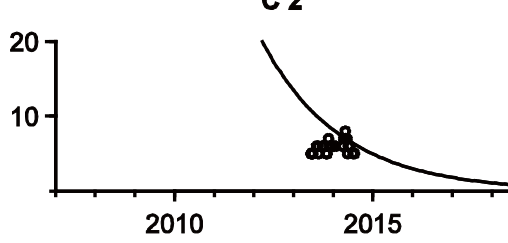

9

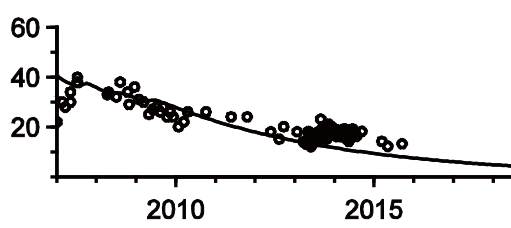

12

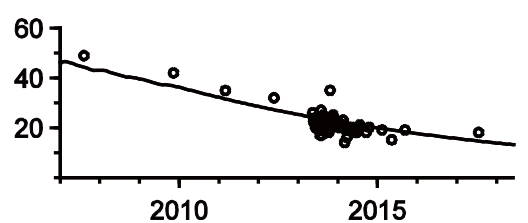

466

467 Figure 6. Observed DEA concentrations and fitted convolution model. DEA was 468 below quantification limit in springs $C 1$ and 11. Points: observations. Line: 469 calculated response of the aquifer using the convolution model.

470 As s-metolachlor was still in use at the end of the sampling period in July 2014, 471 MESA concentrations displayed either increasing trends or stable mean 472 concentrations overlain by large seasonal fluctuations. DEA concentrations were on 473 the contrary decreasing in all springs for which time series started in 2008. For these 
474 time series spanning seven years, the trend appeared clearly above the temporal variability of the signal and could be used to fit the convolution model.

The soil leaching of DEA and MESA simulated with PEARL was used as input time series in equation (6). DT50 values for MESA were those obtained from our degradation experiments, which predicted lower leaching concentrations than those calculated from the PPDB database, and the DT50 estimated by Farlin et al. (2013c) for DEA for the same Luxembourgish soil. The fractions of fields treated at different application frequencies in each recharge area were estimated using records from the Luxembourgish chamber of agriculture covering the period 2006-2012 of the crop grown on a given year for each plot of the country. If the estimated concentrations were too high, all field fractions were reduced by the same amount until an acceptable fit was reached. The parameter $b$ of equation (6) simulating additional formation of TPs in the subsurface was set to 1.7 for atrazine following Farlin et al. (2013c). In the case of MESA, this parameter had not been estimated separately and was added to the calibration. It was also used in that case as scaling factor reflecting the fact that s-metolachlor is only one of the possible substitution products for atrazine and as such would not have been used to treat all corn fields in a given year. That parameter also allows taking an increase or decrease in cultivated corn surfaces between the atrazine and s-metolachlor application periods (i.e. pre and post 2005) in each recharge area into account, but without differentiating between the net effect of changing cultivated surface and percentage of those treated with s-metolachlor. Table 4 summarizes the calibrated mean transit times, the MESA concentrations measured for the last sampling round of the project and the calculated waiting times. As explained in 3.8, fitting of the convolution model is performed either on the DEA decrease over time or on the annual cycle of MESA. Fitting of the convolution model 
499 is questionable for spring 11 where (i) DEA was mostly below quantification limit and 500 could not be used for calibration and (ii) MESA did not display a clear seasonal 501 signal. For other springs such as A3 and 10, the slow rate of DEA decrease does not 502 agree well with the large MESA fluctuations that could only be attributed to the base 503 flow for much shorter $T_{e m}$ values of the weighting function. Lastly, the elevated MESA 504 concentrations in springs B2 and 8 measured in 2008-2010 could not be reproduced 505 if s-metolachlor had been significantly used only after the atrazine ban in 2005.

Table 4. MESA concentrations at the end of the project and estimated mean 507 transit times and waiting times. n.a.: not applicable. The legal drinking water 508 limit of $\mathbf{1 0 0} \mathbf{~ n g / l ~ w a s ~ u s e d ~ a s ~ t a r g e t ~ c o n c e n t r a t i o n ~ t o ~ c a l c u l a t e ~} \mathrm{T}_{2}$ (see equation 509 8)

concentrations 2014

\begin{tabular}{cccccc} 
Spring & {$[\mathrm{ng} / \mathrm{l}]$} & $\mathrm{T}_{\mathrm{em}}[\mathrm{y}]$ & $\mathrm{T}_{\mathrm{pf}}[\mathrm{y}]$ & $\mathrm{T}_{1}$ & $\mathrm{~T}_{2}$ \\
\hline A1 & 82 & 5 & 0 & 2015 & 2014 \\
A2 & 139 & 13.5 & 0 & 2015 & 2019 \\
A3 & 160 & 5 & 0 & 2015 & 2018 \\
B1 & 136 & 8.3 & 0 & 2015 & - \\
B2 & 65 & 10 & 0 & 2015 & 2017 \\
C1 & 334 & 2 & 0.5 & 2015 & 2019 \\
C2 & 807 & 2 & 0 & 2015 & 2023 \\
8 & 678 & 4.2 & 0 & 2015 & 2019 \\
9 & 115 & 4.6 & 2.7 & 2018 & 2019 \\
10 & 206 & 5 & 0 & 2015 & 2024 \\
11 & 250 & 10 & 0 & 2015 & 2015 \\
12 & 360 & 8.3 & 3 & 2018 & \\
\hline
\end{tabular}


511 Two solutes were used to estimate the contribution of recent water (fast flow) to springs discharge from equation (10): deuterium and MESA concentrations. The hydrograph separation approach based on the differences in the signatures of

514 stable isotopes in the slow flow and fast flow reservoirs could not be applied 515 dynamically (i.e. as a function of time) on the entire time series for two reasons. 516 Firstly, assigning each rainfall event and its unique isotopic signature to a particular spring response proved fraught with difficulties, because not all rainfall events caused a spring response, probably due to different antecedent soil moisture conditions. Secondly, the base flow signal displayed in many springs either seasonal variations or a trend over time (Figure 8), thus making the estimation of $\mathrm{C}_{\mathrm{bf}}$ used in equation (8)

521 ambiguous. These two problems made the identification of the rainfall event causing a given spring response impossible without a dynamic modelling approach going

523 beyond the scope of the study. Instead, equation (8) was used to estimate the 524 maximum fast flow contribution from the maximum deviations from the median values 525 measured in each spring and in rainwater. This calculation gave an upper bound to 526 the contribution of recent water during breakthrough events, which was $9 \%$ or less of total discharge. 
A1

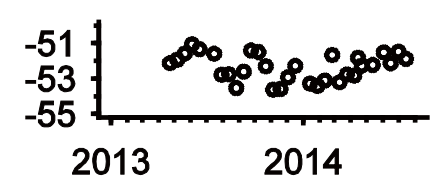

B2

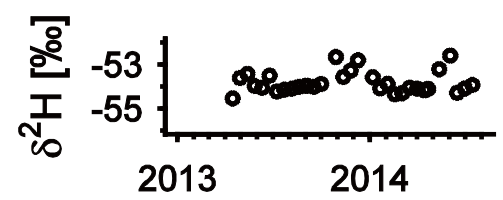

8

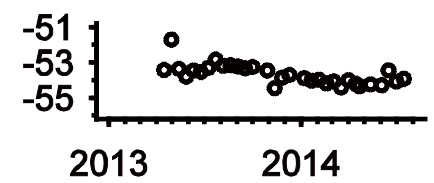

11

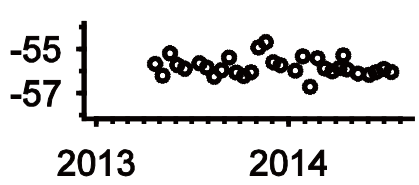

A3

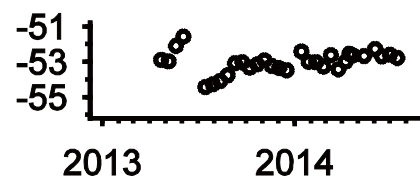

C1

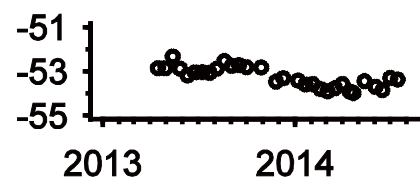

9

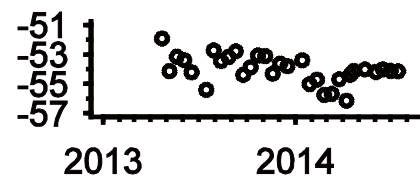

12

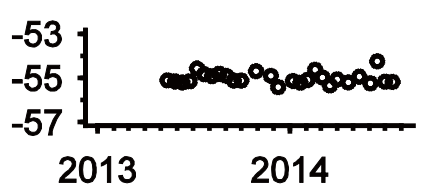

B1

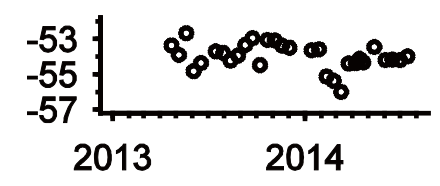

C2

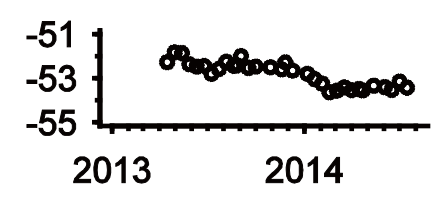

10

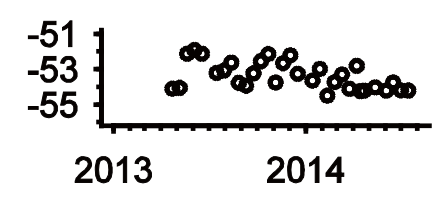

Rain

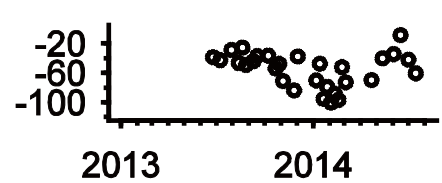

529 Figure 7. Observed deuterium concentrations in the springs and in rain water.

530 Table 5. Maximum contribution of the fast flow component estimated from the

531 maximum deuterium deviation from the median value measured in each spring

532 and in rainwater. The columns contribution 1 and contribution 2 correspond to

533 the contributions calculated respectively from the most and least enriched $\delta^{2} \mathrm{H}$

534 measured in rainwater. n.d.: not determined.

\begin{tabular}{lllll}
\hline Spring & $\delta^{2} \mathrm{H}$ median [\%] & $\delta^{2} \mathrm{H}$ deviation [\%o] & contribution 1 & contribution 2
\end{tabular}

\begin{tabular}{llccc}
\hline A1 & -52 & 2 & $9 \%$ & $4 \%$ \\
A2 & n.d. & - & - & - \\
A3 & -53 & 2 & $8 \%$ & $5 \%$
\end{tabular}




$\begin{array}{lllll}\text { B1 } & -54 & 2 & 8 \% & 5 \% \\ \text { B2 } & -54 & 1.5 & 6 \% & 3 \% \\ \text { C1 } & -53 & 1 & 4 \% & 2 \% \\ \text { C2 } & -53 & 1 & 4 \% & 2 \% \\ 8 & -54 & 2 & 8 \% & 5 \% \\ 9 & -54 & 2 & 8 \% & 5 \% \\ 10 & -54 & 2 & 8 \% & 5 \% \\ 11 & -56 & 1 & 4 \% & 2 \% \\ 12 & -55 & 1 & 4 \% & 2 \%\end{array}$

535

The fast flow contribution was also estimated using the MESA peaks (Table 6). For this we assumed a unique MESA concentration in the fast flow equal to the maximum concentration of $100 \mu \mathrm{g} / \mathrm{l}$ predicted for an annual application in 2013 and 2014 (Figure 3). As shown on Figure 3, the effect of MESA buildup in soils on leaching concentrations is negligible and consequently the same leaching concentration was assumed for all application frequencies. Setting $\mathrm{C}_{\mathrm{ff}}=100 \mu \mathrm{g} / \mathrm{l}$ in equation (10) simulates the case where all corn fields present in the recharge area were treated with s-metolachlor in 2013 or 2014. $\Delta C$ was calculated as the difference between measured MESA peaks and the predicted base flow concentration (see 3.8). The calculated contribution of the fast flow component is much higher in spring 10 than elsewhere $(8.8 \%$ compared to a median value of $1.2 \%)$. This is due to the large calculated $\Delta \mathrm{C}$, which itself is the consequence of a very small predicted contribution of the base flow component. 


\begin{tabular}{|c|c|c|c|c|c|c|}
\hline & & & & $\mathrm{C}_{\mathrm{ff}}$ & $\Delta \mathrm{C}$ & \\
\hline Spring & $\mathrm{a}_{1}[-]$ & $a_{2}[-]$ & $a_{3}[-]$ & [ng/L] & [ng/L] & $Q_{f f}[\%]$ \\
\hline A1 & 0.08 & 0 & 0 & 100000 & 50 & $0.6 \%$ \\
\hline A2 & 0.08 & 0 & 0 & 100000 & 70 & $0.9 \%$ \\
\hline A 3 & 0.15 & 0 & 0 & 100000 & 100 & $0.7 \%$ \\
\hline B 1 & 0.02 & 0.02 & 0 & 100000 & 70 & $1.8 \%$ \\
\hline B 2 & 0.04 & 0 & 0 & 100000 & 60 & $1.5 \%$ \\
\hline C 1 & 0.2 & 0.1 & 0 & 100000 & 100 & $0.3 \%$ \\
\hline C 2 & 0.5 & 0 & 0.1 & 100000 & 700 & $1.2 \%$ \\
\hline 8 & 0.09 & 0 & 0.05 & 100000 & 400 & $2.9 \%$ \\
\hline 9 & 0.05 & 0 & 0 & 100000 & 60 & $1.2 \%$ \\
\hline 10 & 0.01 & 0 & 0.03 & 100000 & 350 & $8.8 \%$ \\
\hline 11 & 0.06 & 0.09 & 0 & 100000 & 70 & $0.5 \%$ \\
\hline 12 & 0.03 & 0.01 & 0.01 & 100000 & 70 & $1.4 \%$ \\
\hline
\end{tabular}

550

551

552

553

\section{Discussion}

The primary question that initiated the study was whether the elevated MESA and MOXA concentrations reported in some of the springs draining the main Luxembourgish aquifer were due to the fast flow or the slow flow component. In the first case, recovery after the ban of the parent compound would be rapid, otherwise waiting times would be much longer. As we have seen, both components seem to contribute significantly to the mass flow observed in spring water, the fast flow contribution being intermittent in some springs $(\mathrm{C} 1,9)$ but explaining at least partially the large seasonal signals at most of the other sites. 


\subsection{Base flow contribution}

Large concentration differences were observed in spring water between MESA and MOXA, with MESA concentrations being between twice and ten times as high in MOXA concentrations. The same order of magnitude has been reported by Hladik et al. (2008) in the Midwestern United States, and contradict the calculated soil leaching concentrations which are nearly identical for the two compounds. Either soil leaching is overestimated, or another MOXA sink plays an important role. As a weak oxanilic acid, MOXA might become bound to soil iron or aluminum through ligand exchange mechanisms by replacing hydroxide ions (Stumm, 1992). Depending on the strength of the sorption, this would either increase retardation and potentially enhance soil degradation compared to MESA, or simply act as an additional sink. A delayed onset of the MOXA breakthrough combined with much lower concentrations could for instance be observed in spring 12 (Figure 4 and Figure 5). MOXA concentrations in the other springs however seem rather stable over time, showing that plateau concentrations have already been reached. MOXA might also be degraded much faster than MESA in the unsaturated or saturated zone, as reported for instance by Baran and Gourcy (2013) on three unsaturated zone samples.

The leaching simulations using the code PEARL have also illustrated the importance of using field specific degradation rates. Differences of an order of two to three between the rates estimated in the degradation experiments and those given in the PPBD database lead to estimated leaching concentrations also differing by a factor two to three. This problem is however less important than the parameterisation of the transit time distribution since the temporal evolution of pesticide concentration in spring water is controlled by the latter, regardlesss of the absolute value of the soil leaching. 
The transit time distributions of the springs were calibrated using the evolution of DEA and MESA concentrations over time. Although potentially attractive because such a calibration yields directly the transit time distribution of pesticides, parameter estimation was in practice hampered by the low signal to noise ratio and the limited length of the available time series. Pesticide time series usually tend to be noisy, much more so than nitrate for instance, often displaying the superposition of a long term trend, seasonal fluctuations, variability at time scales of a few days to weeks and additional random noise. Ideally, the observation period should be long enough to capture clearly either the increasing and plateau concentration phases or the plateau concentration and the onset of the decreasing phase following a pesticide ban. Alternatively, calibration can be performed using either (i) two shorter simultaneous pesticide time series, one decreasing and the other increasing, or (ii) the amplitude of annual fluctuations caused by the pesticide pulse leached from the soil during the groundwater recharge period between November and March. The springs of the case study clearly illustrated these different possibilities but also the limitations of the method. Spring 9 was exemplary of the joint fitting of two time series, with both the decrease of DEA and the increase of MESA concentrations between 2008 and 2014 clearly standing out above signal variability. Spring C1 was a good example of model fitting based solely on the seasonal pesticide cycle, because in that case, the observed variability was both sufficiently large and clearly recognizable above random fluctuations.

For the other springs, the convolution model calibrated first on the DEA decrease predicted a stronger damping of the seasonal MESA signal than was observed. This was particularly obvious for springs $A 3, B 1,8,10$ and 11 . We see two possible explanations for this. Either the peak amplitude of the annual leaching pulse 
predicted using PEARL is overestimated, or the weighting function describing the transit time distribution of pesticides in the aquifer is heavier tailed than the chosen exponential model. Field Koc for the compounds might be closer to the maximum values, which would effectively smooth out the MESA peaks leached from the soil. For the aquifer compartment, tailing effects are known to be caused by back diffusion from immobile water zones into mobile regions (Knorr et al., 2017), and lead to a transit time distribution function giving more weight to the very young and very old components. This weighting could explain both the slower decrease of DEA by a slow release from the porous sandstone matrix into the fracture network and the lesser damping of pesticide pulses compared to the exponential weighting function due to a higher young water fraction. Lastly, fitting the DEA trend has shown that DEA time series covering only the period 2012-2014 such as those available for A1, A3 and C2 contain too little information and that the relatively long observation period of seven years is a minimum given the slow rate of decrease and the amount of random fluctuations.

The estimated waiting times until MESA concentrations have returned to the legal potability limit of $100 \mathrm{ng} / \mathrm{l}$ range from 2017 to 2029. This opens up the opportunity for an a posteriori audit in the coming years to assess the accuracy of these estimates. Parameter estimation and consequently the reliability of waiting time estimates could also be improved by calibrating the transit time distribution on sufficiently long tritium time series.

\subsection{Fast flow contribution}

In order to accommodate both the observed long term trends and the MESA breakthroughs lasting a few weeks and which clearly stand out above the seasonal signal, we adopted a conceptual model consisting of two separate reservoirs, the first 
634 (the fast flow compartment) summing up superficial flowpaths and causing the 635 concentration peaks, and the second (the base flow compartment) corresponding to 636 the aquifer itself and responsible for the long term trend and at least partially for the

637

638 seasonal signal as well. Each compartment contributes both to total spring water discharge and the TP fluxes. The estimated maximum contribution to water discharge from the fast flow compartment ranges from 0.3 to $9 \%$, with lower values obtained using MESA residual concentrations except in spring 10. This is unsurprising since the contribution calculated using deuterium is based on the maximum deviation in spring water and precipitation, thus yielding an upper bound estimate. Given this fact, the contribution calculated for spring 10 from the MESA concentration being as large as the probable upper bound might indicate a problem. As pointed out in 4.3 and 5.1, the large fast flow contribution in spring 10 is the consequence of the long mean transit times necessary to explain the slow DEA decrease in the base flow component. This in turn leads to such a strong damping of the soil leaching signal that the seasonal fluctuations measured in the spring cannot be explained by the base flow contribution anymore. As already mentioned in 5.1, a possible correction would be to use an aquifer weighting function characterised by a more important young fraction and a longer tail.

For the other springs, discharge is mainly sustained by base flow. The small fast flow contribution can however lead to breakthrough concentrations of several hundred nanograms per litre (springs $\mathrm{C} 2$ and 10) in the months following the pesticide leaching period (November to March) because of the high concentrations of pesticide transformation products reaching several hundred micrograms per litre in leaching water during that period. 
658 The numerical simulations using the code PEARL have shown that the potential for

659

660

661

662

663

664

665

666

667

668

669

670

671

672

673

674

675

676

677

678

679

680

681

682

MESA and MOXA storage in soils is relatively limited and the transit time of the fast flow component in the order of two to five months. Thus, once the source of smetolachlor is removed by banning its use, the release of its TPs from corn fields should become negligible within a few months. Consequently, MESA peaks which were observed in some springs in March and April 2014 will most likely disappear in the years following the 2015 ban on s-metolachlor. This stands in stark contrast to the baseflow concentrations which, due to the inertia of the aquifer will decrease slowly over several years, and for some springs will even first increase until a maximum is reached.

\section{Conclusions}

The study presented here integrates field sampling, laboratory experiments and modelling in a complimentary approach leading to estimates of fast flow and base flow contribution to TP concentration and waiting times in contaminated springs. Estimating the waiting time until groundwater recovers from diffuse agricultural pollution by pesticides or transformation products following a ban or a reduction of the source is important both for agricultural advisers as well as water providers and water managers. For the former, waiting time estimates are useful to communicate with farmers and to assess the effectiveness of mitigation measures. For the latter, waiting times of up to a decade may call for the upgrade of raw water treatment facilities to remove the contaminants of concern. Such an upgrade however is costly and can prove unnecessary if the recovery is quicker than the planning and construction of a treatment facility and if mixing with uncontaminated water is a workable temporary solution.

\section{Funding acknowledgement}


683 This study was funded by the Luxembourgish Water Administration.

684

685

686

687

688

689

690

691

692

693

694

695

696

697

698

699

700

701

702

703

704

705

706

707

\section{Bibliography}

Aga, D.S. and Thurman, E.M., 2001. Formation and transport of the sulfonic acide metabolites of alachlor and metolachlor in soil. Environmental Science and Technology, 35: 2455-2460.

ASTA, 2015. Soil map of the Grand Duchy of Luxembourg, 1:25000/1:50000. Administration du Cadastre et de la Topographie, https://www.europeandataportal.eu/data/en/dataset/2702cc74-6df1-4a24b904-5899a6e20b0c.

Baran, N. and Gourcy, L., 2013. Sorption and mineralisation of S-metolachlor and its ionic metabolites in soils and vadose zone solids: Consequences on groundwater quality in an alluvial aquifer (Ain Plain, France). Journal of Contaminant Hydrology, 154: 20-28.

Bayless, R.E. et al., 2008. Simulated fate and transport of metolachlor in the unsaturated zone, Maryland, USA. Journal of Environmental Quality, 37: 10641072.

Boesten, J.J.T.I., 1991. Sensitivity analysis of a mathematical model for pesticide leaching to groundwater. Pest. Sci., 31: 375-388.

Boxall, A.B., Sinclair, C.J., Fenner, K., Kolpin, D. and Maund, S.J., 2004. When synthetic chemicals degrade in the environment. Environmental Science and Technology, 38: 369-375.

Christophersen, N., Neal, C., Hooper, R.P., Vogt, R. and Andersen, S., 1990. Modelling streamwater chemistry as a mixture of soilwater end-members-A step towards second-generation acidification models. Journal of Hydrology, 116(1-4): 307-320. 
Commission, E., 1998. Council directive 98/83/EC of 3 November 1998 on the quality of water intended for human consumption. Official Journal of the European Union, L330: 32-54.

Dinelli, G., Accinelli, C., Vicari, A. and Catizone, P., 2000. Comparison of the persistence of atrazine and metolachlor under field and laboratory conditions. Journal of Agriculture and Food Chemistry, 48(7): 3037-3043.

Dubus, I.G., Brown, C.D. and Boelke, S., 2003. Sources of uncertainty in pesticide fate modelling. Science of the Total Environment, 317: 53-72.

Farlin, J., Bayerle, M., Pittois, D. and Gallé, T., 2017. Estimating pesticide attenuation from water dating and the ratio of metabolite to parent compound. Ground Water, 55(4): 550-557.

Farlin, J. et al., 2013a. Delineating spring recharge areas in a fractured sandstone aquifer (Luxembourg) based on pesticide mass balance. Hydrogeology Journal, 21: 799-812.

Farlin, J. et al., 2013b. Predicting pesticide attenuation in a fractured aquifer using lumped-parameter models. Ground Water, 51(2): 276-285.

Farlin, J. et al., 2013c. Using the long-term memory effect of pesticide and metabolite soil residues to estimate field degradation half-life and test leaching predictions. Geoderma, 207-208: 15-24.

Graham, W.H. et al., 1999. Metolachlor and alachlor breakdown product formation patterns in aquatic field mesocosms. Environmental Science and Technology, 33: 4471-4476.

Hancock, T.C., Sandstrom, M.W., Vogel, R.M.T., Bayless, R.E. and Barbah, J.E., 2008. Pesticide fate and transport through unsaturated zones in five agricultural settings, USA. Journal of Environmental Quality, 37: 1086-1100. 
Hanke, I. et al., 2007. Arzneimittel und Pestizide im Grundwasser. Gas Wasser Abwasser, 3: 187-196.

Hladik, M., Bouwer, E.J. and Roberts, A.L., 2008. Neutral chloroacetamide herbicide degradates and related compounds in Midwestern United States drinking water sources. Science of the Total Environment, 390: 155-165.

Huntscha, S., Singer, H., Canonica, S., Schwarzenbach, R.P. and Fenner, K., 2008. Input dynamics and fater in surface water of the herbicide metolachlor and of its highly mobile transformation product metolachlor ESA. Environmental Science and Technology, 42: 5507-5513.

Kalkhoff, S.J., Kolpin, D., Thurman, E.M., Ferrer, I. and Barceló, D., 1998. Degradation of chloroacetanilide herbicides: the prevalence of sulfonic and oxanilic acid metabolites in lowa groundwater and surface waters. Environmental Science and Technology, 32: 1738-1740.

Knorr, B., Maloszewski, P. and Stumpp, C., 2017. Analytical transport modelling of metabolies formed in dual-porosity media. Environmental Science and Pollution Research, 24: 4447-4456.

Kolpin, D., Kalkhoff, S.J., Goolsby, D.A., Sneck-Fahrer, D.A. and Thurman, E.M., 1997. Occurrence of selected herbicides and herbicide degradation products in lowa's Ground Water. Ground Water, 35: 679-688.

Kolpin, D., Schnoebelen, D.J. and Thurman, E.M., 2004. Degradates provide insight to spatial and temporal trends of herbicides in ground water. Ground Water, 42: 601-608.

Kraft, G.J., Browne, B.A., Devita, D.M. and Mechenich, D.J., 2008. Agricultural polluttant penetration and steady state in thick aquifers. Ground Water, 46: 4150. 
Krutz, L.J., Gentry, T.J., Senseman, S.A., Pepper, I.L. and Tierney, D.P., 2006. Mineralisation of atrazine, metolachlor and their respective metabolites in vegetated filter strip and cultivated soil. Pesticide Management Science, 62: 505-514.

Leistra, M., van der Linden, A.M.A., Boesten, J.J.T.I., Tiktak, A. and van den Berg, F., 2001. PEARL model for pesticide behaviour and emissions in soil-plant systems. Descriptions of the processes in FOCUS PEARL v 1.1.1. AlterraRapport 013, RIVM report 711401009.

Lewis, K.A., Tzilivakis, J., Warner, D. and Green, A., 2016. An international database for pesticide risk assessments and management. Human and Ecological Risk Assessment: An Internation Journal, 22(4): 1050-1064.

Loos, R. et al., 2010. Pan-European survey on the occurrence of selected polar organic persistent pollutants in ground water. Water Research, 44: 4115-4126.

Maloszewski, P., Willibald, S., Zuber, A. and Rank, D., 2002. Identifying the flow systems in a karstic-fissured-porous aquifer, the Schneealpe, Austria, by modelling of environmental ${ }^{18} \mathrm{O}$ and ${ }^{3} \mathrm{H}$ isotopes. Journal of Hydrology, 256: 48-59.

Maloszewski, P. and Zuber, A., 1982. Determining the turnover time of groundwater systems with the aid of environmental tracers, 1. Models and their applicability. Journal of Hydrology, 57: 207-231.

Postigo, C. and Barceló, D., 2015. Synthetic organic compounds and their transformation products in groundwater: Occurrence, fate and mitigation. Science of the Total Environment, 503-504: 32-47.

PPDB, 2013. The Pesticide Properties Data Base (PPBD) developed by the Agriculture \& Environment Research Unit (AERU). University of Hertfordshire. 
Reemtsma, T., Alder, L. and Banasiak, U., 2013. Emerging pesticide metabolites in groundwater and surface water as determined by the application of a multimethod for 150 pesticide metabolites. Water Research, 47: 5535-5545.

SER, 2014. L'agriculture luxembourgeoise en chiffres 2013 (Luxembourgish agriculture in numbers 2013). Luxembourgish Rural Economy Service.

Sidoli, P., Lassabatere, L., Angulo-Jaramillo, R. and Baran, N., 2016. Experimental and modeling of the unsaturated transports of S-metolachlor and its metabolites in glaciofluvial vadose zone solids. Journal of Contaminant Hydrology, 190: 1-14.

Stumm, W., 1992. Chemistry of the Solid-Water Interface. Processes at the MineralWater and Particle-Water Interface in Natural Systems. Wiley: 428.

Webb, M.T. et al., 2008. Variations in pesticide leaching related to land use, pesticide properties, and unsaturated zone thickness. Journal of Environmental Quality, 37: 1145-1157.

Wösten, J.H.M., Lilly, A., Nemes, A. and Le Bas, C., 1999. Development and use of a database of hydraulic properties of European soils. Geoderma 90: 169-185. 